\section{Gastric Wall Invasion Following Transjugular Intrahepatic Portosystemic Stent Shunt Insertion for Variceal Bleeding}

Transjugular intrahepatic portosystemic stent shunt (TIPSS) insertion has been extensively used in the management of the complications of portal hypertension for over 10 years [1]. We report two unusual cases, brought to light during routine endoscopy, that illustrate technical complications of TIPSS not previously reported.

The first case is that of a 60 -year-old man with alcoholic liver disease who presented with refractory esophageal variceal bleeding. A TIPSS procedure was successfully performed followed by coil embolization of the left gastric vein. A subsequent surveillance TIPSS check revealed that the shunt was occluded, and the patient was entered into a variceal banding programme as patency of the TIPSS could not be restored. At endoscopy, two embolization coils were seen emerging from gastric fundal varices, with no stigmata of recent haemorrhage (Figure $\mathbf{1}$ ). The coils were left in situ, and the patient was discharged without complication.

The second patient was a 53-year-old woman with hepatitis $C$ and alcoholic liver disease, who required a TIPSS for gastric variceal bleeding. Coil embolization of the left gastric vein was performed following TIPSS insertion. An endoscopy performed 5 months later as part of liver transplant assessment revealed an embedded coil in the gastric fundus (Figure 2). This was left in situ. The patient had a successful transplant a month later, despite the presence of part of a catheter tip in the portal vein.

These cases illustrate the potential for penetration of the gastric mucosa by material used for coil embolization of gastric varices during a TIPSS procedure. Although the significance of this complication is unclear, it may potentially contribute to further bleeding or technically complicate liver transplantation. It should be noted that, case reports aside [2-5], there are no controlled trials assessing the efficacy of coil embolization in managing variceal bleeding. We advise caution

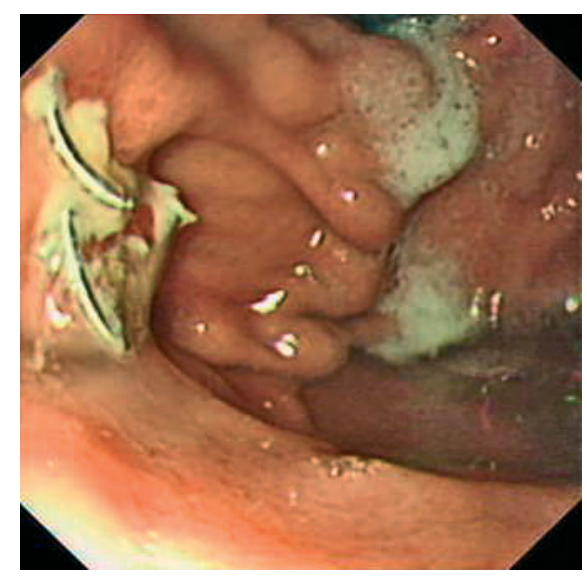

Figure 1 Endoscopic view of embolization coil protruding from gastric fundal varices.

in the use of embolization coils at the time of TIPSS.

D. Tripathi' ${ }^{1}$ J. N. Plevris' ${ }^{1}$, D. N. Redhead ${ }^{2}$, P. C. Hayes ${ }^{1}$

${ }^{1}$ Department of Hepatology, Royal Infirmary of Edinburgh, Edinburgh, Scotland

${ }^{2}$ Department of Radiology, Royal Infirmary of Edinburgh, Edinburgh, Scotland.

\section{References}

${ }^{1}$ Jalan R, Lui HF, Redhead DN et al. TIPSS 10 years on. Gut 2000; 46: $578-581$

2 Kishimoto K, Hara A, Arita T et al. Stomal varices: treatment by percutaneous transhepatic coil embolization. Cardiovasc Intervent Radiol 1999; 22: 523 - 525

${ }^{3}$ Witt WS, Goncharenko V, O'Leary JP et al. Interruption of gastroesophageal varices: steel coil technique. AJR Am J Roentgenol 1980; 135: 829-833

${ }^{4}$ Funaro AH, Ring EJ, Freiman DB et al. Transhepatic obliteration of esophageal varices using the stainless steel coil. AJR Am J Roentgenol 1979; 133: $1123-1125$

${ }^{5}$ Illuminati G, Smail A, Azoulay D et al. Association of transjugular intrahepatic portosystemic shunt with embolization in the treatment of bleeding duodenal varix refractory to sclerotherapy. Dig Surg 2000; 17 : $398-400$

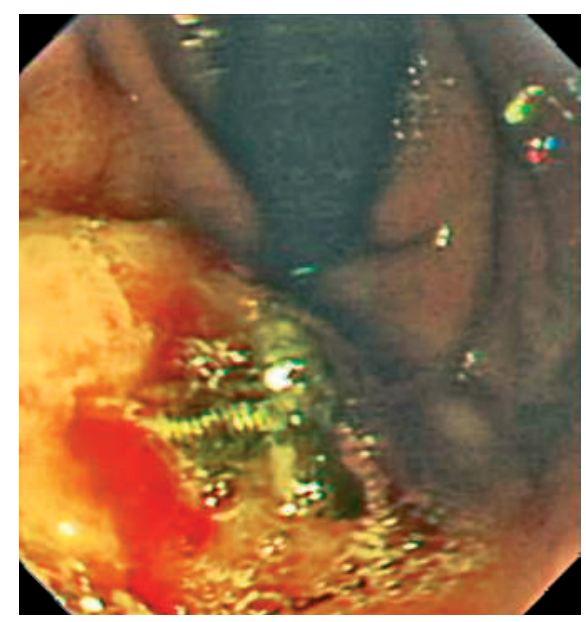

Figure 2 Endoscopic view of embolization coil in gastric mucosa.

\section{Corresponding Author}

\section{Tripathi, M.D.}

Department of Hepatology

Royal Infirmary of Edinburgh

51 Little France Crescent

Edinburgh EH16 4SU

Scotland

Fax: $\quad$ +44-131-2421633

E-mail: tdrdhir@aol.com 